\title{
Nonparametric Multiple Change Point Analysis of the Global Financial Crisis
}

\author{
David E. Allen ${ }^{\mathrm{a}, *}$, Michael McAleer ${ }^{\mathrm{b}}$, Robert J. Powell ${ }^{\mathrm{a}}$, and Abhay K. Singh ${ }^{\mathrm{a}}$ \\ ${ }^{a}$ School of Accounting, Finance and Economics, Edith Cowan University, Australia \\ ${ }^{b}$ Econometric Institute, Erasmus School of Economics, Erasmus University Rotterdam, Tinbergen Institute, The \\ Netherlands, Department of Quantitative Economics, Complutense University of Madrid, Spain, and Institute of \\ Economic Research, Kyoto University, Japan
}

\begin{abstract}
This paper presents an application of a recently developed approach by Matteson and James (2012) for the analysis of change points in a data set, namely major financial market indices converted to financial return series. The general problem concerns the inference of a change in the distribution of a set of time-ordered variables. The approach involves the nonparametric estimation of both the number of change points and the positions at which they occur. The approach is general and does not involve assumptions about the nature of the distributions involved or the type of change beyond the assumption of the existence of the $\alpha$ absolute moment, for some $\alpha \in(0,2)$. The estimation procedure is based on hierarchical clustering and the application of both divisive and agglomerative algorithms. The method is used to evaluate the impact of the Global Financial Crisis (GFC) on the US, French, German, UK, Japanese and Chinese markets, as represented by the S\&P500, CAC, DAX, FTSE All Share, Nikkei 225 and Shanghai A share Indices, respectively, from 2003 to 2013. The approach is used to explore the timing and number of change points in the datasets corresponding to the GFC and subsequent European Debt Crisis.
\end{abstract}

Keywords: Nonparametric Analysis, Multiple Change Points, Cluster Analysis, Global Financial Crisis.

JEL: G11, C02.

\section{Introduction}

The impact of the Global Financial Crisis (GFC) and subsequent European Debt Crisis on global financial markets is an important concern for investors, economic policy makers and regulators around the world. The nature of the transmission and timing of the impact of the crisis on individual national financial markets has been the source of much interest and research, given that financial markets are leading indicators of economic activity.

There is also a long history in the economics literature of business cycle analysis, the timing of which is a key concern for national governments and economic policy makers. For example, the National Bureau of Economic Research in the USA views recessions or contractions as starting at the peak of a business cycle and ending at the trough, and in the case of the GFC suggest a period starting in December 2007 and ending in June 2009. This dating is based on a 'rule of thumb' because identifying the date of the trough involves weighting the behavior of various indicators of economic activity. The estimates of real GDP and GDI issued by the Bureau of Economic Analysis of the U.S. Department of Commerce are only available quarterly. Furthermore, macroeconomic indicators are subject to substantial revisions and measurement error.

There is also a wide variety of statistical and econometric techniques available for the analyis of business cycles (see the discussion in Diebold and Rudebusch (1996)). Burns and Mitchell (1946, p.3) defined business cycles as "a type of fluctuation found in the aggregate economic activity of nations that organize their work mainly in business enterprises: a cycle consists of expansions occurring at about the

\footnotetext{
*Allen and Powell acknowledge the funding support of the Australian Research Council. For financial support, McAleer wishes to thank the Australian Research Council, National Science Council, Taiwan, and Japan Society for the Promotion of Science.

Email address: d.allen@ecu.edu.au (David E. Allen)
} 
same time in many economic activities, followed by similarly general recessions, contractions, and revivals which merge into the expansion phase of the next cycle". A pioneer of econometric work on business cycles was Tinbergen (1939). Stock and Watson (1989, 1991, 1993) used a dynamic factor model to capture comovement of relevant economic series by obtaining a single common factor from a set of many macroeconomic series. Hamilton (1989) estimated a nonlinear model for real GNP with discrete regime switching between periods of expansion and contraction. A survey of more recent work is provided by Harding and Pagan (2008).

In the finance literature, one of the most popular empirical techniques for assessing the informational impact of an 'event' is the ubiquitous 'event' study. This was pioneered by Fama et al. (1969) in a famous study of stock splits, and by Ball and Brown (1968) in their analysis of the impact of changes in accounting numbers. Mackinlay (1997), in a survey of event studies, mentions that event studies have many applications in accounting and finance research. They have been applied to a variety of firm-specific and economy-wide events. Some examples include mergers and acquisitions, earnings announcements, issues of new debt or equity, and announcements of macroeconomic variables such as the trade deficit.

The efficacy of an event study depends, in part, on the properties of the economic model used to set equilibrium returns (see the discussion in Coutts et al. (1995)). The empirical approach in this paper could be contrasted with those of a traditional event study, even though the focus of both is a shared concern about the impact of newsworthy event(s). In a typical event study, the model used to estimate returns is presumed to hold over both the estimation period and subsequent event period. The statistical framework is provided by the use of ordinary least squares regression, so the Gauss Markov assumptions are presumed to hold across the sample period. In the approach taken in this paper, no such assumptions are used and the technique requires that distributional parameters change, so that change points can be distinguished. This is the opposite of the convention adopted in event studies, which requires that distributions remain Gaussian.

This paper is concerned with financial markets and the analysis of changes in their behavior induced by crises. Dungey et al. (2010) analysed whether financial crises are alike and the process of contagion using a model based on excess returns on financial assets. Allen et al. (2013) analysed volatility spillovers across the GFC using financial return series and a GARCH framework incorporating VARMA-GARCH, VARMA-AGARCH and time-varying correlations. The economics literature has tended to focus on the timing of crises and the identification of their peaks and troughs. The finance literature has focused on the impact of individual events, in terms of positive or negative reactions in the form of average adjusted 'equilibrium' return series, in the event studies literature, or in the transmission of volatility shocks in the GARCH literature. There is a discrepancy in these two approaches. The event studies literature is built upon the assumption of homoscedasticity in the market model regression, while the GARCH model is built upon conditional heteroscedasticity in the form of $\mathrm{ARCH}$ effects.

This paper has a different focus. It is not concerned with the identification of the peaks and troughs, as is the case in traditional business cycle analysis, and it does not seek to model the transmission of shocks or regime changes, as captured by changes in parameters within a model. Its focus is broader and concentrates on discernible distribution changes which mark break points in a series. The approach is non-parametric and is not based on a particular assumption about the underlying distribution of the return series. It requires that series are not homoscedastic and that they have time-varying properties. In this sense, it involves assumptions that are the reverse of a traditional event study.

The paper addresses a central concern in research in empirical finance. The nature of the return and covariance structure of financial assets is a focal point of much empirical and theoretical work in finance. The general problem of estimating the covariance structure of multivariate data is of fundamental importance in effecting the statistical analysis of data sets. In research in empirical finance, the estimation of the covariance matrix sits at the centre of empirical research in asset pricing, portfolio selection and investment strategies which use market data.

One approach to modelling these changes has focused on the use of the multivariate stochastic volatility models of Jacquier et al. (1994). Another approach is to apply graphical techniques, as in Talih (2003). This graphical approach has also featured in the work on Vine copulas proposed by Joe (1996) and developed in greater detail in Bedford and Cooke (2001, 2002) and Kurowicka and Cooke (2006). Vines are a flexible graphical model for describing multivariate copulas built up using a cascade of bivariate copulas, so-called pair-copulas. Their statistical breakthrough was due to Aas, Czado, Frigessi and Bakken (2009), who described statistical inference techniques for the two classes of canonical C-vines and Dvines. These belong to a general class of Regular Vines, or R-vines, which can be depicted in a graphical theoretic model to determine which pairs are included in a pair-copula decomposition. Therefore, a vine is a graphical tool for labelling constraints in high-dimensional distributions. 
Talih and Hengartner (2005) present an alternative approach to those models that focus instead on the hidden graphical structure that is related to the precision matrix. They mention that the latter is the inverse of the covariance matrix, which is a natural parameter in the multivariate normal model, and which is also intimately related to the coefficients in the simultaneous regression of each variable on all the remaining variables. This means that they can develop a graphical model for sequences of Gaussian random vectors when changes take place in the underlying graph, which is specified by zeros in the precision matrix, occuring at random times, and producing a new block of data that is created with the addition or deletion of an edge. Matteson and James (2012) build upon this general approach applying cluster analysis to identify positions where distributional changes occur, signifying changes or 'edges' of a block of data. We use their approach and their R package 'ecp' to undertake the analysis in this paper.

The paper is divided into five sections: section 2 provides a review of the background theory and models applied, section 3 introduces the sample, section 4 discusses the results, and a conclusion follows in section 5 .

\section{Background and models}

\subsection{The general framework}

Matteson and James (2012) recently developed a non-parametric procedure for fitting multiple change points to multivariate data. Change point analysis is the process of assessing distributional changes within time ordered observations. This is a useful technique for the analysis of financial data (see Talih and Hengartner (2005)), and can be undertaken parametrically or non-parametrically. Parametric analysis requires the underlying distributions to belong to some known family, and is based on the application of the likelihood function ( see Carlin et al. (1992) and Lavielle and Teyssiere (2006) for examples). An alternative approach involves nonparametric methods, which are applicable across a wider range of applications than parametric ones (Hariz et al., 2007), and rely on the estimation of density functions.

The method developed by Matteson and James (2012) takes a different approach and is based on Euclidean distances between sample observations. They suggest that it is simple to calculate and avoids the difficulties associated with multivariate density estimation. They develop a new method that can detect any distributional change, and which does not make any distributional assumptions beyond the existence of the $\alpha$ absolute moment, for some $\alpha \in(0,2)$. Estimation is performed in a manner that simultaneously identifies both the number and locations of change points. Their estimation procedure is done in a manner that simultaneously identifies both the number and location of change points.

They develop the following framework: let $Z_{1}, Z_{2}, \ldots ., Z_{T} \in \mathbb{R}^{d}$ be an independent sequence of time-ordered observations. In the simplest case, there is a single hypothesized change point location $\tau$. In which $Z_{1}, \ldots \ldots, Z_{\tau} \stackrel{i i d}{\sim} F_{1}$ and $Z_{\tau+1}, \ldots . Z_{T}, \stackrel{i i d}{\sim} F_{2}$, and where $F_{1}$ and $F_{2}$ are unknown probability distributions. They then test for homogeneity in distributions: $H_{0}: F_{1} \stackrel{D}{=} F_{2}$ versus $H_{A}: F_{1} \neq F_{2}$. They extend this approach to a more general framework in which the number of change points as well as their locations are unknown, and develop a nonparametric technique termed E-Divisive for the performance of multiple change point analysis of a sequence of multivariate observations.

\subsection{Measuring differences in multivariate distributions}

Matteson and James (2012) proceed by letting $(t, x)$ denote the scalar products of vectors $t, x \in \mathbb{R}^{d}$. For complex valued functions $\phi(\cdot)$, the complex conjugate of $\phi$ is denoted by $\bar{\phi}$, and the absolute square $|\phi|^{2}$ is defined as $\phi \bar{\phi}$. The Euclidean norm of $x \in \mathbb{R}^{d}$ is $|x|_{d}$. A primed variable such as $X^{\prime}$ is an independent copy of $X$; that is, $X$ and $X^{\prime}$ are independent and identically distributed (iid).

For random variables $X$ and $Y \in \mathbb{R}^{d}$, let $\phi_{x}$ and $\phi_{y}$ denote the characteristic functions of $X$ and $Y$, respectively. As a divergence measure between multivariate distributions, Matteson and James (2012) suggest:

$$
\int_{\mathbb{R}^{d}}\left|\phi_{x}(t)-\phi_{y}(t)\right|^{2} w(t) d t
$$

in which $w_{t}$ denotes an arbitrary weight function, for which the integral in (1) above exists. They suggest a convenient weight function may be defined as:

$$
w(t ; \alpha)=\left(\frac{2 \pi^{d / 2} \Gamma(1-\alpha / 2)}{\left.\alpha 2^{\alpha} \Gamma(d+\alpha) / 2\right)}|t|^{d+\alpha}\right)^{-1} d t
$$


for some fixed consstant $\alpha \in(0,2)$. Then if $E|X|^{\alpha}, E|Y|^{\alpha}<\infty$, for $X, Y \mathbb{R}^{d}$, a characteristic function based divergence measure may be defined as:

$$
D(X, Y ; \alpha)=\int_{\mathbb{R}^{d}}\left|\phi_{x}(t)-\phi_{y}(t)\right|^{2}\left(\frac{2 \pi^{d / 2} \Gamma(1-\alpha / 2)}{\left.\alpha 2^{\alpha} \Gamma(d+\alpha) / 2\right)}|t|^{d+\alpha}\right)^{-1} d t
$$

They suppose that $X, X^{\prime} \stackrel{i i d}{\sim} f_{x}$ and $Y, Y^{\prime} \stackrel{i i d}{\sim} f_{y}$ and that $X, X^{\prime}, Y$, and $Y^{\prime}$ are mutually independent. If $E|X|^{\alpha}, E|Y|^{\alpha}<\infty$, then they define an alternative divergence measure between multivariate distributions based on Euclidean distances as:

$$
\varepsilon(X, Y ; \alpha)=2 E|X-Y|^{\alpha}-E\left|X-X^{\prime}\right|^{\alpha}-E\left|Y-Y^{\prime}\right|^{\alpha}
$$

The above can be used to obtain an empirical divergence measure for multivariate distributions based on U-statistics. This approach is expanded to develop a test for the existence of multiple change points. Matteson and James (2012) provide examples of applications of the procedure to genetics and financial datasets. They use just under 22 years of monthly returns data for Cisco systems for the financial data set. In their analysis, they specify $\alpha=1$, a minimum cluster size of 30 observations and use $R=499$ permutations with a level of $p_{0}=0.05$ in their significance testing. In their data set, they discovered 2 significant break points.

We adopt their test procedure in this paper as a means of assessing the impact of the GFC and related subsequent events on a sample of 10 years of daily returns for 6 major market indices.

\section{Sample}

We use a data set of daily returns, which runs from 14/4/2003 to 12/4/2013 using logarithmic return series in local currencies constructed for the S\&P500 Index, FTSE All share Index, Dax, CAC, Nikkei 225 and Shanghai SE A share price indices. A summary of the sample and descriptive statistics for the series is shown in Table 1.

\begin{tabular}{|c|c|c|c|c|c|c|c|c|}
\hline Index & Mean & Median & Min & Max & Standard Deviation & $\mathrm{CV}$ & Skewness & Kurtosis \\
\hline S\&P500 (SPRET) & 0.00023151 & 0.00047987 & -0.094695 & 0.10957 & 0.012716 & 54.926 & -0.32255 & 11.251 \\
\hline FTSE All Share (FTSERET) & 0.00023419 & 0.00027605 & -0.087099 & 0.088107 & 0.011595 & 49.513 & -0.22336 & 8.2633 \\
\hline CAC (CACRET) & 0.00010463 & 0.00024885 & -0.094715 & 0.10595 & 0.014334 & 137.00 & 0.041834 & 6.9262 \\
\hline DAX (DAXRET) & 0.00039895 & 0.00067120 & -0.074335 & 0.10797 & 0.014043 & 35.199 & 0.022578 & 6.4799 \\
\hline NIKKEI 225 NIKRET) & 0.00020895 & 0.00000 & -0.12111 & 0.13235 & 0.015009 & 71.830 & -0.57208 & 9.3848 \\
\hline SHANGHAI SE A (SHRET) & 0.00012891 & 0.00000 & -0.092608 & 0.090332 & 0.016278 & 126.28 & -0.25705 & 3.8536 \\
\hline
\end{tabular}

Table 1: Sample Index Logarithmic Return Series, 14/4/2003 - 12/4/2013

The descriptive statistics representing the daily returns for the whole sample period on the five indices shown in Table 1 are typical of return series. They display evidence of skewness and kurtosis. The French and Chinese markets have high coefficients of variation, but their mean daily returns are very low. The median return in China and Japan is zero, while the German Dax mean daily return is the highest during this period, and the French CAC return is the lowest.

The purpose of the analysis undertaken in this paper is to explore the impact of major financial market events, in particular the GFC and the subsequent European debt crisis, and to examine how they impact on the return series representing these major markets. We explore whether they lead to distinct segmentation, or discernible distribution changes for the individual series during the sample period.

The time series plots for the return series and the QQ plots of the series are shown in Figures 1 and 2, respectively. The QQ plots reveal sharp deviations from a normal distribution in the tails of all the series. 
Figure 1: Plots of the return series

(a) The S\&P500

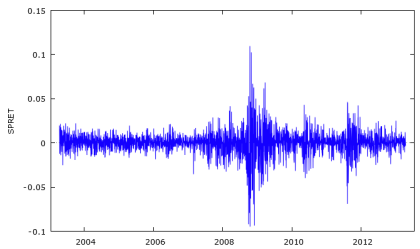

(d) The DAX index

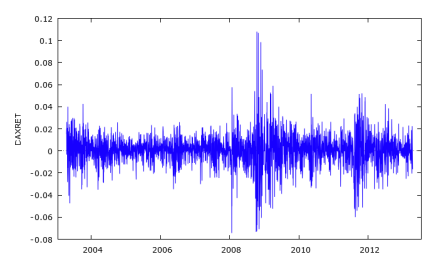

(b) The FTSE All Share

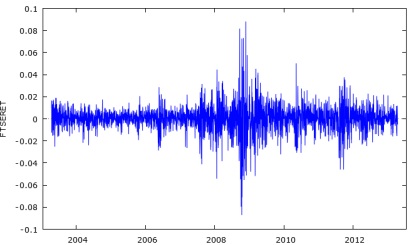

(e) The NIKKEI 225

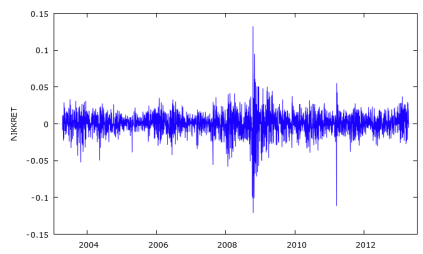

(c) The CAC index

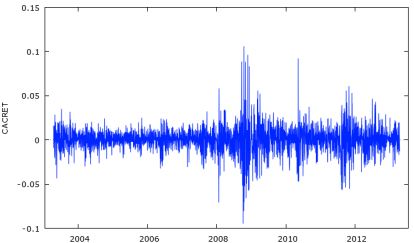

(f) The SHANGHAI A

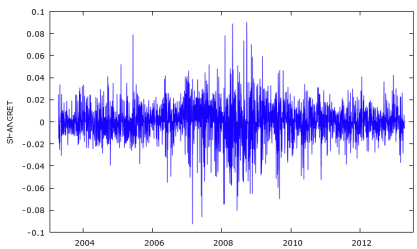

The QQ plots are shown in Figure 2 below.

Figure 2: QQ Plots of Index return series

(a)

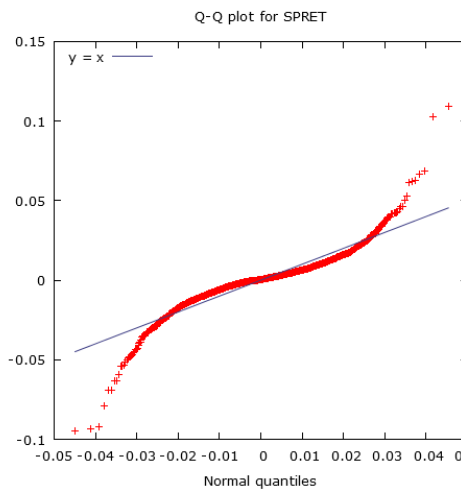

(d)

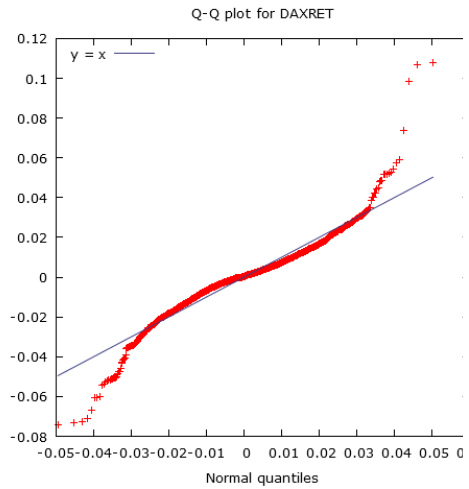

(b)

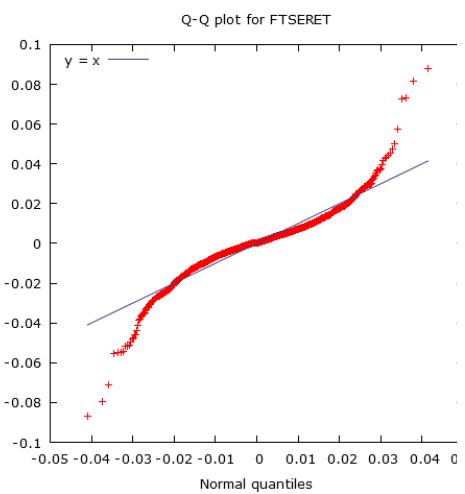

(e)

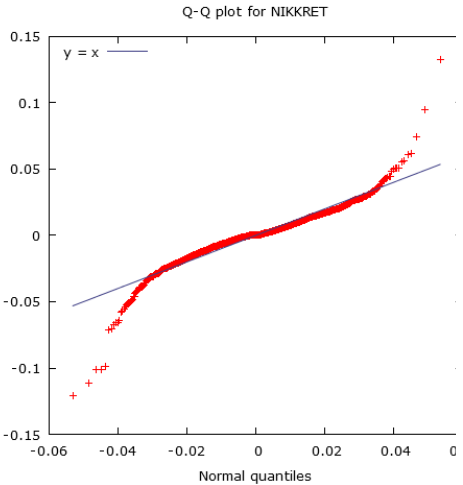

(c)

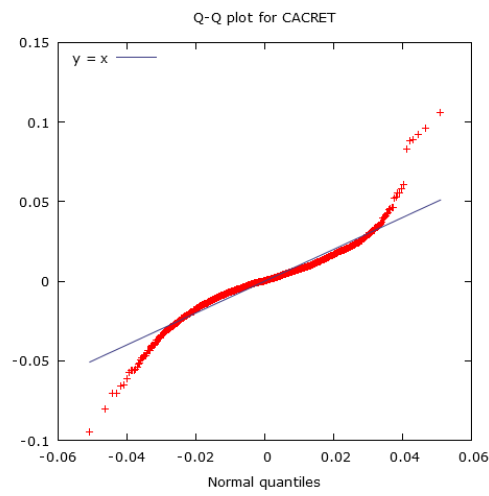

(f)

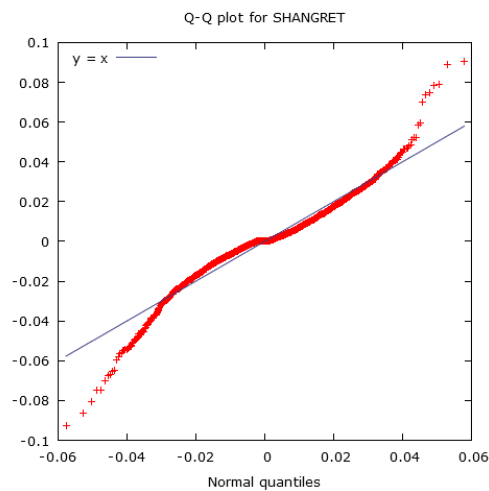

All the series deviate sharply from the blue horizontal line in the diagrams shown in Figure 2, which represents the quantile plot for normal distributions. The deviations are apparent in the tails of the return distributions.

The subsequent analysis presented in section 4 shows how the sample can be divided in the various markets into distinct segments based on the differences in the distributional characteristics of the data set within the sample subsets. 


\section{Results}

The tests for the existence of multiple change points are based on the individual series of index returns on our sets of 2610 sets of individual observations of daily continuously compounded returns for the six stock market indices. Table 2 shows the results of applying the Matteson and James (2012) divisive hierarchical algorithm for change point analysis within the Matteson and James (2013) R package 'ecp' to our sample series of six sets of market index returns.

Table 2: Results of the breakpoint tests for the index return series

\begin{tabular}{|c|c|c|c|c|c|c|}
\hline Index & \multicolumn{7}{|c|}{ Breakpoint dates } \\
\hline \hline SPRET & $20 / 7 / 2007$ & $4 / 9 / 2008$ & $10 / 4 / 2009$ & $12 / 4 / 2013$ & & \\
\hline probability & 0.005 & 0.005 & 0.045 & 0.125 & & \\
\hline FTSERET & $18 / 7 / 2007$ & $3 / 9 / 2008$ & $8 / 4 / 2009$ & $12 / 4 / 2013$ & & \\
\hline probability & 0.005 & 0.005 & 0.005 & 0.08 & & $12 / 4 / 2013$ \\
\hline CACRET & $14 / 7 / 2007$ & $30 / 8 / 2008$ & $5 / 12 / 2008$ & $28 / 7 / 2011$ & $11 / 12 / 2011$ & 0.435 \\
\hline probability & 0.005 & 0.005 & 0.010 & 0.025 & 0.005 & $12 / 4 / 2013$ \\
\hline DAXRET & $4 / 11 / 2003$ & $2 / 1 / 2008$ & $8 / 9 / 2008$ & $8 / 3 / 2009$ & $1 / 8 / 2011$ & 0.360 \\
\hline probability & 0.005 & 0.005 & 0.005 & 0.005 & 0.030 & \\
\hline NIKRET & $16 / 10 / 2007$ & $30 / 9 / 2008$ & $21 / 11 / 2008$ & $20 / 5 / 2009$ & $12 / 4 / 2013$ & \\
\hline & 0.005 & 0.005 & 0.005 & 0.005 & 0.135 & \\
\hline SHANGRET & $14 / 11 / 2006$ & $17 / 10 / 2007$ & $21 / 5 / 2009$ & $7 / 12 / 2009$ & $12 / 42003$ & \\
\hline & 0.005 & 0.005 & 0.005 & 0.005 & 0.17 & \\
\hline
\end{tabular}

The results in Table 2 vary considerably. The S\&P500 return index, FTSE and CAC all date the first change point to the end of the second week or within the third week of July 2007.

\subsection{Potential economic factors behind the dating of change points}

There were a number of significant financial events in 2007 which included a plunge in housing values in the USA, which was the steepest since 1989. In the first quarter of 2007, the S\&P/Case-Shiller house price index recorded the first year-over-year nationwide decline since 1991. The subprime mortgage industry collapsed, plus a surge of foreclosure activity (twice as much as in 2006) and rising interest rates threatened to depress prices further. The problems in the subprime markets spread to the near-prime and prime mortgage markets.

In February 2007, Europe's biggest bank, HSBC Holdings, blamed soured US subprime loans for its first-ever profit warning, and subsequently, on September 21, 2007, it announced the closure of its US subprime unit, Decision One Mortgage, and recorded an impairment charge of about $\$ 880$ million. Meanwhile, in the USA, during February and March 2007, more than 25 subprime lenders filed for bankruptcy. In April 2007, New Century, a US subprime lender filed for Chapter 11 bankruptcy protection in the biggest collapse of a mortgage lender in the crisis. On June 12, 2007, Bear Stearns suspended redemptions from the 10-month-old High-Grade Structured Credit Strategies Enhanced Leverage Fund, which as of April 30, was down $23 \%$ for the quarter. On June 29, 2007, the Federal Reserve issued a Statement on Sub Prime Lending setting new standards for underwriting, disclosure and risk management relating to sub prime lending.

Meanwhile, in Europe in July 2007, two banks in Germany, IKB and state bank SachsenLB, suffer exposure from investing in the US subprime market. The German banking industry bailed out IKB, but SachsenLB almost went under and was quickly sold to state-backed Landesbank Baden-Wuerttemberg (LBBW).

This led to the consideration of a puzzle in terms of our series breakpoints. July 2007 is clearly very important in terms of marking a breakpoint for three of our major financial markets, namely USA, UK and France. However, the first German breakpoint in the dataset is in November 2003. This coincides with a period of relatively poor economic growth in Europe. In 2003 the 12 economies of the Euro area were projected to record a 0.5 per cent growth rate. Both The Netherlands and Portugal were in decline. Germany was in stasis and France's GDP was projected to increase by only 0.5 per cent. Partly as a result of the impact of re-unification, the German government deficit rose above the ' $3 \%$ of GDP' ceiling set in the Stability and Growth Pact, meaning that Germany was placed in the 'excessive deficit procedure' for four consecutive years (2002-2005). Thus, presumably, concerns about the German economy in 2003 were picked up by this breakpoint. 
Meanwhile, in 2007, the GFC continued to unfold. On August 9, 2007, BNP Paribas, the French bank, barred investors from redeeming cash in $\$ 2.2$ billion worth of funds, after informing the markets that it was unable to calculate the value of the three funds due to turmoil in the subprime market. On August 17, 2007 the markets for securitized mortgage products froze and this led to further liquidity and valuation problems.

For the UK markets, a very significant event took place on September 13, 2007. This was the date that Northern Rock, a British mortgage lender, experienced a bank run following a credit crunch sparked by the subprime crisis. The Bank of England stepped in to rescue it. Thus, the turbulence experienced in these markets is not surprising.

A number of the financial market series in the analysis, namely USA, UK, Germany, Japan and France, record breakpoints around August to September 2008. There were a number of key financial events during this period. On September 7, 2008 there was the Federal takeover of Fannie Mae and Freddie Mac and a pledge $\$ 200$ Billion of support. On September 14, 2008 Merrill Lynch was sold to the Bank of America amid fears of a liquidity crisis. Lehman Brothers collapsed and on September 15 Lehman Brothers filed for bankruptcy protection. On the same day, Moody's and Standard and Poor's downgraded ratings on AIG's credit over concerns about continuing losses to mortgage-backed securities, sending the company into fears of insolvency. The following day the US Federal Reserve loaned $\$ 85$ billion to American International Group (AIG) to avoid bankruptcy. On September 19, Henk Paulson, the US Treasury Secretary revealed a financial rescue plan after a volatile week in stock and debt markets. The US Treasury temporarily guaranted money market funds against losses up to $\$ 50 \mathrm{~B}$. On September 25, 2008 Washington Mutual was seized by the Federal Deposit Insurance Corporation, and its banking assets were sold to JP Morgan Chase for $\$ 1.9 \mathrm{bn}$. The period October 6-10, 2008 marked the worst week for the stock market in 75 years. The Dow Jones Index lost 22.1 percent, its worst week on record, and was down 40.3 percent since reaching a record high of $14,164.53$.

The first breakpoint in the Shanghai index series was recorded on November 14, 2006. Real GDP growth was $11.6 \%$ in China in 2006, peaking in 2007 at $13 \%$. The market could be picking up changes in expectations but it is not clear why a breakpoint occurred at this point. The breakpoint in October 2007 lagged those in other markets by a few months. In 2007, the interbank offered rate officially started operation in Shanghai, representing the faster marketization of the formation of the interest rate. The next breakpoint was in May 2009. In February 2009, China's state-owned Chinalco invested $\$ 19.5$ billion in the Anglo-Australian mining company Rio Tinto, increasing its stake from 9\% to 18\%. On July 2 , 2009, the State Council, or China's Cabinet, announced a pilot program to allow exporters and importers to settle cross-border trade deals in Renminbi, or yuan, in the cities of Shanghai, Guangzhou, Shenzhen, Zhuhai and Dongguan. In November 2009, China produced 13.79 million units of automobiles, of which 10.38 million units were passenger cars and 3.41 million units were commercial vehicles, making it the world's largest market. In December 2009, a new gas pipe was announced between Turkmenistan and China. The pipeline will deliver to China 40 billion cubic meters of natural gas per year and was expected to reach its full capacity by 2013. This amounts to an estimated 50\% of China's total 2007 natural gas production.

Figure 3 shows the dating of the change points in the six series. 
(a) S\&P500 change points

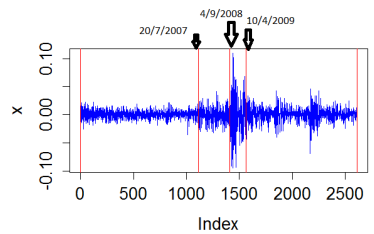

(d) DAX change points

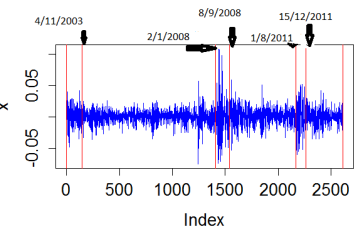

(b) FTSE change points

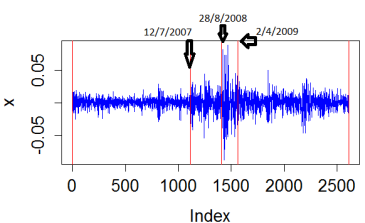

(e) NIKKEI change points

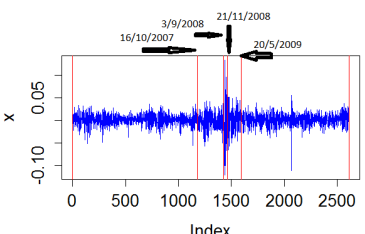

(c) CAC change points

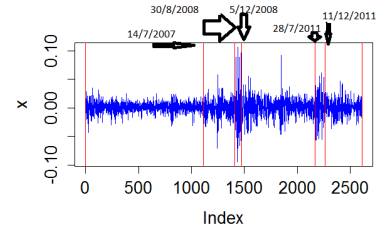

(f) SHANGHAI change points

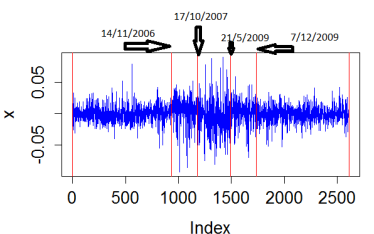

\subsection{Statistical characteristics of the identified sub-periods}

\subsubsection{Mandelbrot's Multifractal Model of Asset Returns (MMAR)}

Mandelbrot et al. (1997) developed a Multifractal Model of Asset Returns (MMAR), which views the price of an asset as a multiscaling process with long memory and long tails. Fluctuations in volatility in the MMAR are introduced by a random trading time, generated as the c.d.f. of a random multifractal measure. Mandelbrot et al. (1997) proceed as follows:

Let $\{B(t)\}$ be a stochastic process, and $\theta(t)$ be an increasing function of $t$. The process

$$
X(t) \equiv B[\theta(t)]
$$

is called a compound process. The index $t$ denotes clock time, and $\theta(t)$ is called trading time or the time deformation process. A special form of the compound process is called subordination which, as part of the theory of Markov processes, requires that $\theta(t)$ has independent increments. The MMAR suggests that trading time is a c.d.f. of a multifractal measure. This suggests that trading time will be highly variable and will possess long memory.

The MMAR model proceeds by suggesting the price of a financial asset $\{P(t) ; 0 \leq t \leq T\}$ is determined using the following notation:

$$
X(t)=\ln P(t)-\ln P(0)
$$

and assumes that $X(t)$ is a compound process:

$$
X(T)=B_{H}[\theta(t)]
$$

where $B_{H}[\theta(T)]$ is a fractional Brownian Motion with self-affinity under $\mathrm{H}$, and $\theta(t)$ is stochastic trading time which is the c.d.f of a multifractal measure defined on $[0, T]$. That is, $\theta(t)$ is a multifractal process with continuous, non-decreasing paths, and stationary increments. Furthermore; $\left\{B_{H}(t)\right\}$ and $\{\theta(t)\}$ are independent.

Mandelbrot et al. (1997) suggest that trading time, $\theta(t)$, plays a crucial role in the model in that $\theta(0)=0$ since, by definition, $X(0)=0$. A second implication is that $\theta(t)$ is the cumulative distribution function of a self-similar random measure, such as a binomial or a multiplicative measure. Trading time $\theta(t)$ causes the price $X(t)$ to be multifractal, and the scaling function $\tau_{x}(q)$ and $\tau_{\theta}(q)$ to be closely related. This leads to the result that under the previously mentioned assumptions, the process $X(t)$ is multifractal, with scaling function $\tau_{x}(q) \equiv \tau_{\theta}(H q)$.

\subsubsection{Properties of the MMAR model}

The MMAR model possesses certain tail properties. The multiscaling mechanism adopted suggests that if $E|X(t)|^{q}$ is finite for some instant $t$, it is finite for all $t$. This means that the time index can be omitted when discussing the moments of multifractal processes. The $q-t h$ moment of $X$ exists if the 
process $\theta$ has a moment of order $H q$. The MMAR model has enough flexibility to accommodate a wide variety of tail behaviour. One important issue is correlation in the process increments.

For a fixed $\Delta t>0$ and any process $Z$, define

$$
Z(t, \Delta t)=Z(t+\Delta t)-Z(t)
$$

and the covariance function:

$$
\gamma z(t)=\operatorname{Cov}[Z(a, \Delta t), Z(a+t, \Delta t] .
$$

As $Z(t)$ has stationary increments, we know that $\gamma z(t)$ does not depend on the choice of $a$. Consider the special case where $H$, or the Hurst index $H=1 / 2$, in which $B_{H}(t)$ is a Brownian motion. Mandelbrot et al. (1997) demonstrate that if $B_{H}(t)$ is a Brownian motion without drift, the following properties hold:

1. If $E\left(\theta^{1 / 2}\right)$ is finite, then $\{X(t)\}$ is a martingale with respect to its natural filtration.

2. If $E \theta$ is finite, the increments of $X(t)$ are uncorrelated. That is, $\gamma x(t)=0$, for all $t \geq \Delta t$.

Thus, when $H=1 / 2$ the MMAR generates a price process that has a white noise spectrum. This is built upon the properties of Brownian motion and does not extend to the cases where $H \neq 1 / 2$. Indeed, Mandelbrot et al. (1997) demonstrate that if $E\left(\theta^{2 H}\right)$ is finite, the autocovariance function of the price process $X(t)$ satisfies, for all $t \geq \Delta t$ :

$$
\left.\gamma x(t)=K\left\{(t+\Delta t)^{m}+t-\Delta t\right)^{m}-2 t^{m}\right\}
$$

where $m=\tau_{\theta}(2 H)+1$ and $k=c_{\theta}(2 H) \operatorname{Var}\left[B_{H}(1)\right] / 2$. It is positive when $H>1 / 2$ and negative when $H<1 / 2$.

We use the MMAR model to evaluate our results and, in particular, the value of the Hurst exponent in the last column of Table 4 . If this value shifts from greater than 0.5 to less than 0.5 , it suggests a change in the dependence of the series from positive to negative. We shall discuss the Hurst exponent further in the next subsection in the light of Mandelbrot's (2003) fractal approach to asset pricing. Table 3 provides a comparison and summary of some of the common models of financial returns.

\begin{tabular}{|c|c|c|}
\hline $\begin{array}{c}\text { Volatility clustering } \\
\text { implies predictable } \\
\text { price }\end{array}$ & $\begin{array}{c}\text { Volatility clustering } \\
\text { consistent with } \\
\text { martingale price }\end{array}$ & Properties \\
\hline ARMA* & GARCH & $\begin{array}{l}\text { no long memory } \\
\text { Scale-inconsistent }\end{array}$ \\
\hline ARFIMA* & FIGARCH & $\begin{array}{c}\text { long memory } \\
\text { scale-inconsistent }\end{array}$ \\
\hline FBM & MMAR & $\begin{array}{c}\text { long memory } \\
\text { scale-consistent }\end{array}$ \\
\hline
\end{tabular}

Table 3: Comparisons of models of financial returns

(a) Typical characteristics

(b) Typical covariance characteristics of models of returns

\begin{tabular}{|c|c|c|}
\hline Model & $\operatorname{Cov}\left(\left|X_{t+s+\Delta t}-X_{t+s}\right|,\left|X_{t+\Delta t}\right|\right)$ & $\operatorname{Cov}\left(X_{t+s+\Delta t}-X_{t+s}, X_{t+\Delta t}\right)$ \\
\hline ARMA & weak & weak \\
\hline GARCH & weak & zero \\
\hline ARFIMA & strong & strong \\
\hline FIGARCH & strong & zero \\
\hline FBM & strong & strong \\
\hline MMAR & strong & zero or strong \\
\hline \multicolumn{2}{|c|}{ Source: Mandelbrot et al. (1997, p.23) } \\
\hline
\end{tabular}




\subsubsection{The results}

The S\&P500 return series was divided into 4 periods from 2003 to $20 / 7 / 2007$, then to $4 / 9 / 2008$, next to $10 / 4 / 2009$, finally terminating at the end of the sample on $12 / 4 / 2013$. The summary statistics for these sub-periods are provided in Table 3 below. It is apparent that, in the different sub-periods identified, the mean return on the S\&P500 switches from positive to negative, the median return moves from positive to zero, the standard deviation varies from under $1 \%$ to to nearly $3.5 \%$, the coefficient of variation moves across a range from 13.327 to 18.115 , the skewness changes from positive to negative, and the excess kurtosis ranges from 0.34 to 3.45. These values are all consistent with distributional changes, but the measure of greatest interest is the Hurst exponent. In the case of S\&P500, the Hurst index is above 0.5 in the first period, then drops to 0.45 , then switches back to 0.53 , and finally to 0.50 . This suggests a sequence of periods with positive, negative, and positive dependence, followed in the last period by behaviour resembling Brownian motion.

The FTSE return is also divided into four distinct periods in which the mean returns switch from positive $0.05 \%$ to two periods of small negative values, finally returning to positive $0.04 \%$. The standard deviation and coefficient of variation vary markedly, with the highest standard deviation of $2.8 \%$ in the third period identified, while the last period has the highest coefficient of variation. The skewness is consistently negative and kurtosis has a relative peak of 1.83 in the first period. The Hurst index for FTSE shows a great deal of variation, with a low value of 0.43 in the first period indicating negative dependence, then moving to 0.49, and 0.51, consistent with Brownian motion, before moving to 0.52 in the last period.

CAC also shows a great deal of variation across the 6 sub-periods identified, with half the periods having positive mean returns of a low order, yet the maximum daily return is as high as $10 \%$. The highest standard deviation occurs in the last 3 months of 2008 , where it reaches $3.9 \%$. The coefficient of variation peaks in the next 6 months, with a value of 62.7 . The first two periods display negative skewness, which then becomes positive for the next 4 periods. Kurtosis is variable, peaking at 3.87 in the period 2008-2011. The Hurst index is very low for the first period, from $14 / 4 / 2003$ to $14 / 7 / 2007$, with a value of 0.448 , which is consistent with negative dependence. It then moves to 0.50 and vacillates around 0.5 , though the fourth period identified, from $1 / 9 / 2008$ to $5 / 12 / 2008$, has too few observations to permit its calculation.

DAX also displays 6 different significantly different periods during this ten-year sample frame. The mean returns are relatively low, with the highest mean daily return of $0.2 \%$ in the first period from $14 / 4 / 2003$ to $4 / 11 / 2003$. The highest standard deviation in any of the periods is in the 5 th period, at $2.58 \%$, which runs from $2 / 8 / 2011 /$ to $15 / 12 / 2011$. Positive skewness is evident in 4 of the 6 periods. The kurtosis is most extreme in the 4 th period, from $9 / 9 / 2008$ to $10 / 8 / 2011$. The Hurst index varies greatly, and is negative at 0.48 in the first period, and then becomes consistently positive, peaking at 0.60 in the 3 rd period from $3 / 1 / 2008$ to $8 / 9 / 2008$. There is strong evidence of positive dependency in DAX.

Nikkei is segmented into 5 distinct periods. The mean returns are negative, apart from in the first and last periods. The standard deviation peaks at $4.7 \%$ in the $3 r d$ period, from 4/9/2008 to 21/11/2008. Apart from the third period, the skewness is always negative. The kurtosis peaks in the last period, $21 / 5 / 2009$ to $12 / 4 / 2013$. The Hurst index is uniformly greater than 0.5 , apart from the $3 \mathrm{rd}$ period, which lacked a sufficient number of observations to permit calculation. In the 4th period, 22/11/2008 to $20 / 5 / 2009$, the Hurst index has a value of 0.595 , indicating strong dependency.

The Shanghai index behaves differently from the rest of the series. The analysis indicates 5 distinct subperiods in which the mean return is low, and negative in 3 of them. The standard deviation peaks at $2.4 \%$ daily in the 3 rd period, from $18 / 10 / 2007$ to $21 / 5 / 2009$. There is negative skewness in all periods, apart from the first. Kurtosis peaks at 1.97 in the 4 th period, from 22/5/2009 to $7 / 12 / 2009$. The most noticeable difference between the Chinese market and the others is the relative high values of the Hurst index in all periods. It is above 0.6 in 3 of the periods and there were insufficient observations to permit calculation in the 2 nd period from $15 / 112006$ to $17 / 10 / 2007$. It peaks at 0.664 in the third period, from $18 / 10 / 2007$ to $21 / 5 / 2009$. In the last period, from $8 / 12 / 2009$ to $12 / 4 / 2013$, it sits at 0.535 . These values suggest there is greater dependency in the Chinese market than in the other markets.

Thus, contrary to popular empirical assumptions about security price behaviour, the markets studied in this ten-year window appear to experience striking changes, displaying significantly different behaviour in terms of fractal dimensions, as captured by change point analysis and the Hurst index, which suggest that the common assumption of uniform distributional behaviour in empirical financial analysis is not justified. The behaviour observed appears more consistent with the MMAR model suggested by Mandelbrot et al. (1997). 
Table 4: Summary statistics for changepoint sub-periods

\begin{tabular}{|c|c|c|c|c|c|c|c|c|c|c|}
\hline Index & $\begin{array}{l}\text { Sub- } \\
\text { period }\end{array}$ & mean & median & minimum & maximum & $\begin{array}{l}\text { Standard } \\
\text { deviation }\end{array}$ & C.V. & Skewness & Ex. Kurtosis & $\begin{array}{l}\text { Hurst } \\
\text { Expo- } \\
\text { nent }\end{array}$ \\
\hline \multirow[t]{4}{*}{ SPRET } & $\begin{array}{l}14 / 4 / 2003- \\
20 / 7 / 2007\end{array}$ & 0.00052196 & 0.00068193 & -0.035343 & 0.022138 & 0.0069563 & 13.327 & -0.12392 & 0.99945 & 0.530147 \\
\hline & $\begin{array}{l}21 / 7 / 2007- \\
4 / 9 / 2008\end{array}$ & -0.00065373 & 0.0 & -0.032519 & 0.041535 & 0.012854 & 19.663 & 0.022358 & 0.34642 & 0.449314 \\
\hline & $\begin{array}{l}5 / 9 / 2008- \\
10 / 4 / 2009\end{array}$ & -0.00255 & 0.0 & -0.0947 & 0.10957 & 0.034287 & 13.464 & 0.067553 & 0.82676 & 0.538057 \\
\hline & $\begin{array}{l}11 / 4 / 2009- \\
12 / 4 / 2013\end{array}$ & 0.00062909 & 0.00052939 & -0.068958 & 0.046317 & 0.011396 & 18.115 & -0.39948 & 3.4466 & 0.500854 \\
\hline \multirow[t]{4}{*}{ FTSERET } & $\begin{array}{l}14 / 4 / 2003- \\
12 / 7 / 2007\end{array}$ & 0.0005638 & 0.00064115 & -0.028655 & 0.028653 & 0.0067823 & 12.03 & -0.38186 & 1.8348 & 0.434649 \\
\hline & $\begin{array}{l}12 / 7 / 2007- \\
28 / 8 / 2008\end{array}$ & -0.00066514 & 0.0 & -0.054183 & 0.044592 & 0.013997 & 21.044 & -0.075048 & 0.79407 & 0.498534 \\
\hline & $\begin{array}{l}9 / 29 / 2008- \\
4 / 2 / 2009\end{array}$ & -0.0020493 & -0.00098765 & -0.087099 & 0.088107 & 0.028006 & 13.666 & -0.075081 & 1.3482 & 0.50888 \\
\hline & $\begin{array}{l}4 / 3 / 2009- \\
12 / 04 / 2013\end{array}$ & 0.00049372 & 0.00016421 & -0.045938 & 0.05026 & 0.010776 & 21.827 & -0.16021 & 1.7526 & 0.517115 \\
\hline \multirow[t]{6}{*}{ CACRET } & $\begin{array}{l}14 / 4 / 2003- \\
14 / 7 / 2007\end{array}$ & 0.000692 & 0.000666 & -0.04353 & 0.035111 & 0.008899 & 12.86 & -0.30836 & 1.4567 & 0.448569 \\
\hline & $\begin{array}{l}15 / 4 / 2007- \\
30 / 8 / 2008\end{array}$ & -0.0007106 & $-1.56 \mathrm{E}-05$ & -0.070774 & 0.058335 & 0.0136 & 19.139 & -0.28102 & 2.569 & 0.503531 \\
\hline & $\begin{array}{l}1 / 9 / 2008- \\
5 / 12 / 2008\end{array}$ & -0.0049221 & -0.0022978 & -0.094715 & 0.10595 & 0.039558 & 8.0369 & 0.43793 & 0.70644 & $\mathrm{n} / \mathrm{a}$ \\
\hline & $\begin{array}{l}6 / 12 / 2008- \\
28 / 7 / 2011\end{array}$ & 0.00024174 & 0.0 & -0.056331 & 0.092208 & 0.015154 & 62.687 & 0.34313 & 3.8772 & 0.512662 \\
\hline & $\begin{array}{l}29 / 7 / 2011- \\
11 / 12 / 2011\end{array}$ & -0.0019333 & -0.002942 & -0.056346 & 0.060891 & 0.02533 & 13.102 & 0.017909 & -0.15708 & 0.48141 \\
\hline & $\begin{array}{l}12 / 12 / 2011- \\
2 / 4 / 2013\end{array}$ & 0.0005307 & 0.00041138 & -0.036494 & 0.046411 & 0.012647 & 23.83 & 0.012499 & 0.89609 & 0.511699 \\
\hline \multirow[t]{6}{*}{ DAXRET } & $\begin{array}{l}14 / 4 / 2003- \\
4 / 11 / 2003\end{array}$ & 0.0021544 & 0.0019003 & -0.047408 & 0.04253 & 0.015995 & 7.4242 & -0.21912 & 0.020101 & 0.484356 \\
\hline & $\begin{array}{l}5 / 11 / 2003- \\
2 / 1 / 2008\end{array}$ & 0.000707 & 0.001079 & -0.035162 & 0.026051 & 0.0091996 & 13.017 & -0.39833 & 0.9419 & 0.502164 \\
\hline & $\begin{array}{l}3 / 1 / 2008- \\
8 / 9 / 2008\end{array}$ & -0.0015366 & -0.00055918 & -0.074335 & 0.05761 & 0.014954 & 9.7318 & -0.45184 & 3.968 & 0.602368 \\
\hline & $\begin{array}{l}9 / 9 / 2008- \\
10 / 8 / 2011\end{array}$ & 0.00016551 & 0.00040941 & -0.073355 & 0.10797 & 0.018967 & 114.59 & 0.34951 & 5.8683 & 0.539874 \\
\hline & $\begin{array}{l}2 / 8 / 2011- \\
15 / 12 / 2011\end{array}$ & -0.0023899 & -0.0045502 & -0.059947 & 0.052104 & 0.025827 & 10.806 & 0.051734 & -0.4638 & 0.560114 \\
\hline & $\begin{array}{l}16 / 12 / 2011- \\
12 / 4 / 2013\end{array}$ & 0.0008437 & 0.00076612 & -0.034773 & 0.042401 & 0.011329 & 13.428 & -0.0756 & 1.2522 & 0.54595 \\
\hline \multirow[t]{5}{*}{ NIKRET } & $\begin{array}{l}14 / 4 / 2003- \\
16 / 10 / 2007\end{array}$ & 0.00067842 & 0.00014619 & -0.055695 & 0.036031 & 0.011357 & 16.74 & -0.45732 & 1.8324 & 0.529184 \\
\hline & $\begin{array}{l}17 / 10 / 2007- \\
3 / 9 / 2008\end{array}$ & -0.0013709 & -0.0003518 & -0.058157 & 0.041823 & 0.016638 & 12.136 & -0.23847 & 0.4679 & 0.539912 \\
\hline & $\begin{array}{l}4 / 9 / 2008- \\
21 / 11 / 2008\end{array}$ & -0.0080647 & -0.0078225 & -0.12111 & 0.13235 & 0.047317 & 5.8672 & 0.14391 & 0.73972 & $\mathrm{n} / \mathrm{a}$ \\
\hline & $\begin{array}{l}22 / 11 / 2008- \\
20 / 5 / 2009\end{array}$ & -0.00093821 & 0.0 & -0.12111 & 0.13235 & 0.02691 & 28.682 & -0.25325 & 4.0305 & 0.595637 \\
\hline & $\begin{array}{l}21 / 5 / 2009- \\
12 / 4 / 2013\end{array}$ & 0.00036603 & 0.0 & -0.11153 & 0.055223 & 0.012871 & 35.164 & -0.72823 & 6.1061 & 0.552177 \\
\hline \multirow[t]{5}{*}{ SHANGRET } & $\begin{array}{l}14 / 4 / 2003- \\
14 / 11 / 2006\end{array}$ & 0.00018347 & 0.0 & -0.055089 & 0.079014 & 0.012372 & 67.432 & 0.42157 & 0.42157 & 0.62048 \\
\hline & $\begin{array}{l}15 / 11 / 2006- \\
17 / 10 / 2007\end{array}$ & 0.0085926 & 0.0098431 & -0.038133 & 0.04618 & 0.018108 & 2.1074 & -0.23848 & 0.31521 & $\mathrm{n} / \mathrm{a}$ \\
\hline & $\begin{array}{l}18 / 10 / 2007- \\
21 / 5 / 2009\end{array}$ & $-8.72 \mathrm{E}-05$ & 0.00095159 & -0.092608 & 0.090332 & 0.024115 & 276.53 & -0.29444 & 1.5224 & 0.664817 \\
\hline & $\begin{array}{l}22 / 5 / 2009- \\
7 / 12 / 2009\end{array}$ & 0.0014949 & 0.0031156 & -0.069856 & 0.046819 & 0.018787 & 12.568 & -0.90423 & 1.9754 & 0.614537 \\
\hline & $8 / 12 / 2009-$ & -0.00044943 & 0.0 & -0.052884 & 0.042429 & 0.011916 & 26.514 & -0.26762 & 1.8628 & 0.535272 \\
\hline
\end{tabular}


Mandelbrot et al. (1997) commented on the the existence of some similarities between the FIGARCH model of Baillie et al. (1996) and the MMAR model. They summarised the comparisons in the following manner shown in Figure 4. They suggest that the most important properties of the model are that the MMAR has long memory in volatility, is compatible with the martingale property of asset returns, is scale consistent, and exhibits multi-scaling. The MMAR model can thus be viewed as an alternative to GARCH models. Like FIGARCH, it incorporates long memory in volatility. It also allows the property that returns are uncorrelated, but does not require it. Its main advantage over FIGARCH is its property of scale consistency. Aggregation properties of the data, which can be viewed as information obtained at different sampling frequencies, can be used to test the model.

This aggregation property has been used in this paper to construct the Hurst indices. We have proposed that our approach sits naturally within the MMAR framework. Our results are suggestive, as we have not estimated an MMAR model. Fisher, Calvert and Mandelbrot (1997), in their work on Deutschemark/US dollar exchange rates, use $\log / \log$ plots to check for linearity and fit their MMAR model. A non-parametric technique is used in this paper to identify change points and the construction of the Hurst index is done via linear logarithmic regressions that are consistent with the approach used in fractal estimation.

\section{Conclusion}

In this paper we have used the recently developed non-parametric technique developed by Matteson and James (2012) to distinguish differences in the distributions of returns on six major market indices for a set of ten years daily continuously compounded returns from 2003-2103, which incorporate the GFC. The results for the US, French, German, UK, Japanese and Chinese markets, as represented by the S\&P500, CAC, DAX, FTSE All Share, Nikkei 225 and Shanghai A share Indices, respectively, suggest multiple distribution changes in the sample period for all six markets. The descriptive statistics for these identified sub-periods support the ability of the method to distinguish between periods characterised by different moments and Hurst indices. The latter measure suggests switches from positive to negative dependency in different periods, and some of these sub-periods and markets are characterised by strong dependency. This variation in distributional characteristics requires a flexible model of returns to incorporate this variety of effects. One suitable model is the MMAR model suggested by Mandelbrot et. al (1997). 


\section{References}

[1] Aas, K., Czado, C., Frigessi, A., and H. Bakken (2009) "Pair-copula constructions of multiple dependence", Insurance, Mathematics and Economics, 44, 182-198.

[2] Allen, D.E., R. Amram and M. McAleer (2013) "Volatility spillovers from the Chinese stock market to economic neighbours", Mathematics and Computers in Simulation, forthcoming.

[3] Ball, R., and P. Brown (1968) "An empirical evaluation of accounting income numbers," J. Acc. Res. , 6(2), 159-78.

[4] Baillie, R.T., Bollerslev, T., and H.O. Mikkelson (1996) "Fractionally integrated generalised autoregressive conditional heterscedasticity", Journal of Econometrics, 74, 3-30.

[5] Bedford, T. and R.M. Cooke (2001) "Probability density decomposition for conditionally dependent random variables modeled by vines", Annals of Mathematics and Articial Intelligence, 32, 245-268.

[6] Bedford, T. and R.M. Cooke (2002) "Vines - a new graphical model for dependent random variables", Annals of Statistics, 30, 1031-1068.

[7] Burns, A.F., and W.C. Mitchell (1946) Measuring Business Cycles, New York, National Bureau of Economic Research.

[8] Carlin, B.P., Gelfand, A.E., and A.F. Smith (1992), "Hierarchical Bayesian analysis of changepoint problems", Applied Statistics, 41, 389-405.

[9] Coutts, A., T.C. Mills, and J. Roberts (1995) "Misspecification of the market model: the implications for event studies", Applied Economics Letters, 2, 163-165.

[10] Diebold, F., and G.D. Rudebusch (1996) "Measuring business cycles: A modern perspective", Review of Economics and Statistics, 78, 67-77.

[11] Dungey, M., R. Fry, B. González-Hermosillo, V.L. Martin and C. Tang (2010) "Are financial crises alike?", IMF Working Paper, WP/10/14.

[12] Fama, E., Fisher, L., Jensen, M. and R. Roll (1969) "The adjustment of stock prices to new information", International Economic Review, 10, 1-21.

[13] Hamilton, J. D., (1989) "A new Approach to the economic analysis of nonstationary time series and the business cycle", Econometrica, 57, 357-384.

[14] Harding, D., and A.R. Pagan (2008) "Business cycle measurement", in S.N. Durlauf and L.E. Blume (eds), The New Palgrave Dictionary of Economics (2nd Edition), Palgrave Macmillan.

[15] Jacquier, E., Polson, N.G. and P.E. Rossi (1994) "Bayesian analysis of stochastic volatility models (with discussion)", Journal of Business and Economic Statististics, 12, 371-417.

[16] James, N.A., and D.S. Matteson, (2013) "ecp: An R package for nonparametric multiple change point analysis of multivariate data", Technical report, Cornell University.

[17] Kurowicka, D. and R.M. Cooke (2006) "Uncertainty analysis with high dimensional dependence modelling", Chichester: John Wiley.

[18] Lavielle, M., and Teyssiere, G. (2006) "Detection of multiple change-points in multivariate time series", Lithuanian Mathematical Journal, 46, 287-306.

[19] Mackinlay, A.C. (1997) "Event studies in economics and finance", Journal of Economic Literature, XXXV, 13-39.

[20] Mandelbrot, B. (2003) "Heavy tails in finance for independent or multifractal price increments". Handbook on Heavy Tailed Distributions in Finance, Edited by Svetlozar T. Rachev (Handbooks in Finance: 30, Senior Editor: William T. Ziemba). 
[21] Mandelbrot, B., P.M. Laurent Calvet and A. Fisher (1997) "The multifractal model of asset returns", Cowles Foundation Discussion Papers, 1164.

[22] Matteson, D.S. and N.A. James, (2012) "A nonparametric approach for multiple change point analysis of multivariate data", Working Paper, Department of Statistical Science, Cornell University.

[23] National Bureau of Economic Research, "US business cycle expansions and contractions", http://www.nber.org/cycles/US_Business_Cycle_Expansions_and_Contractions_20120423.pdf

[24] Stock, J.H. and M.W. Watson (1989) "New indexes of coincident and leading economic indicators", in O. Blanchard and S. Fischer (eds.), NBER Macroeconomics Annual, Cambridge, Mass, MIT Press, 351-394.

[25] Stock, J. H. and M. W. Watson (1991) "A probability model of the coincident economic indicators" in K. Lahiri and G.H. Moore (eds.), Leading Economic Indicators: New Approaches and Forecasting Records, Cambridge: Cambridge University Press, 63-89.

[26] Stock, J.H., and M.W. Watson (1993) "A procedure for predicting recessions with leading indicators: econometric issues and recent experience," in J.H. Stock and M.W. Watson (eds.), Business Cycles, Indicators and Forecasting, Chicago: University of Chicago Press for NBER, 255-284.

[27] Talih, M. (2003) "Markov random fields on time-varying graphs, with an application to portfolio selection", PhD Thesis. Department of Statistics, Yale University, New Haven.

[28] Talih, M. and N. Hengartner (2005) "Structural learning with time-varying components: tracking the cross-section of financial time series", Journal of the Royal Statistical Society, Series B, 67,3, 321-341.

[29] Tinbergen, J. (1939) Statistical testing of business cycle theories, Volume II: Business Cycles in 29 the United States of America, 1919-1932, Geneva: League of Nations. 